\title{
Eggs at breakfast increase satiety and reduce the subsequent intake of energy at lunch and an evening meal relative to cereal or croissant-based breakfasts
}

\author{
L. Wilson, R. Fallaize, J. Gray, L. M. Morgan and B. A. Griffin \\ Faculty of Health \& Medical Sciences, University of Surrey, Guildford, Surrey GU2 7XH, UK
}

There is much interest in identifying foods that have the ability to enhance satiety as a strategy for preventing obesity. The aim of this study was to determine the relative impact of egg, and non-egg-based breakfasts on satiety, hunger and subsequent intake of energy. Thirty healthy, non-smoking, unrestrained males (mean age of $21.7 \pm 1.2 \mathrm{y}$ and BMI of $23.1 \pm 2.7 \mathrm{~kg} / \mathrm{m}^{2}$ ), were randomised to one of three iso-caloric test breakfasts on three separate occasions, separated by at least one week. The breakfasts consisted of either two poached eggs on white toast, cereal (cornflakes) with milk and white toast, or a croissant and orange juice. Subjective ratings of satiety (hunger, fullness and desire to eat), were assessed by the responses to three questions (Q1-Q3), as measured by electronic visual analogue scales (VAS) at 30 minute intervals for 3.5 hours between breakfast and lunch. Energy intake was measured by weighed food intake at an ad libitum buffet lunch and evening meal.

\section{Satiety ratings after egg $(\bullet)$, cereal $(0)$ and croissant-based $(\Delta)$ breakfasts}

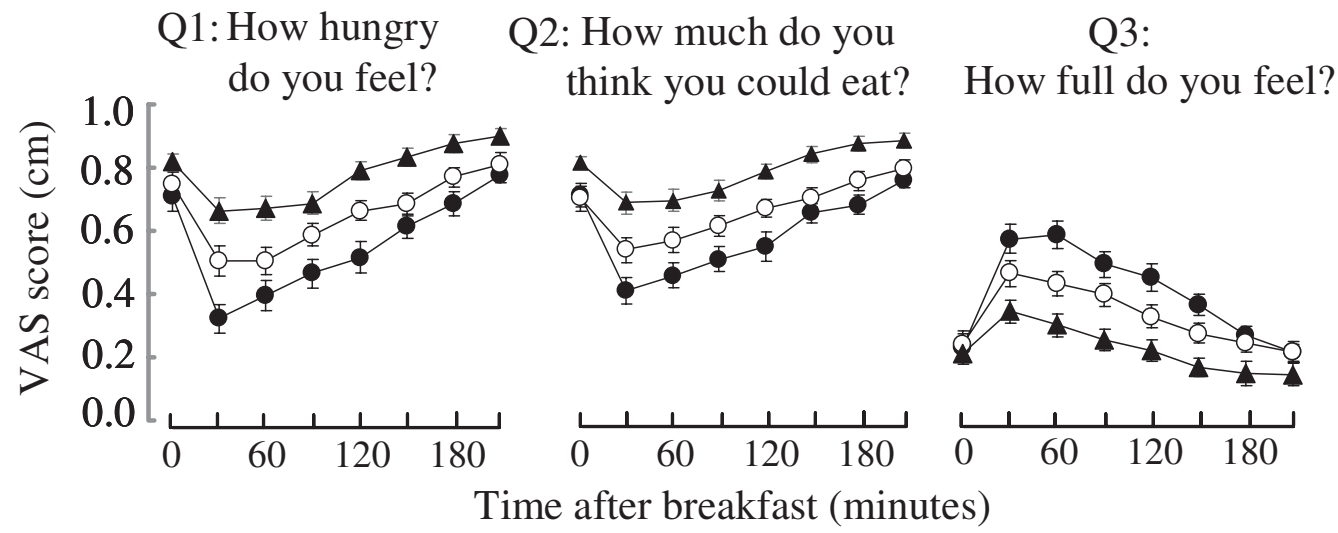

Participants showed increased satiety, less hunger, and a lower desire to eat after the egg breakfast relative to the cereal $(P<0.02)$ and croissant-based breakfasts $(P<0.0001)$. The egg-based breakfast was also accompanied by a significantly lower intake of energy at the buffet lunch and evening meal relative to the cereal and croissant-based breakfasts, respectively $(1284 \pm 464$ versus $1442 \pm 426 \mathrm{kcal}$ $P=0.03$ (lunch) and $1899 \pm 729$ versus $2214 \pm 620 \mathrm{kcal}, P=0.02$ (evening meal)). The consumption of eggs at breakfast clearly enhanced satiety and reduced energy intake at subsequent meals relative to other commonly consumed breakfast foods. These data provide evidence to support the inclusion of eggs in dietary strategies to lose weight. 